\title{
The Impacts of the Namibian School Admission Policy on High School Learners
}

\author{
Article by Memoir Chimwamurombe ${ }^{1}$, Ndinaani Mwashita ${ }^{2}$ \\ ${ }^{1}$ Ph.D, Texila American University - Guyana \\ ${ }^{2}$ Ph.D, Midlands State University - Zimbamwe \\ E-mail: mchimwa@gmail.com ${ }^{1}$,mndinaani@yahoo.com ${ }^{2}$
}

\begin{abstract}
The impacts of the Namibian School Admission Policy on high school learners have major contributions to social problems experienced by stakeholders as learners advance with their education. Social problems such as sexual relations, substance abuse and learner drop-out have become a social trend. However, other factors like peer pressure and poverty should not be overlooked. Learners admitted in schools after the age of six (6) experience problems that makes them vulnerable. This leads to high academic failure rate, teenage pregnancy, drug addiction that eventually compromises the quality of education. Learners become adults whilst in high school and this conflict with policies and regulations in Namibia. The aim of this study was to scrutinize the impacts of the Namibian School Admission Policy on social behavior of leaners as they reach high school. A quantitative research method was used with learners from Grade 8 to 12 from five state secondary schools in Windhoek. The sample had 200 participants who were randomly chosen. A pilot study was used to test the instrument's reliability. Data was collected using a closed questionnaire. Ethical considerations were implemented throughout the research process. Chi-square correlations and descriptive analysis were used to analyze data. Results were in the context of the study. Recommendations were given to address the observed social problems.
\end{abstract}

Keywords: policies, impact, adolescents and behavior.

Alternative hypothesis: The admission policy has an impact on high school learners in Namibia.

Null Hypothesis: The admission policy has no impact on high school learners in Namibia.

\section{Introduction}

Social ills among high school learners have been of concern to many countries in Africa (Lloyd and Hewett, 2009). Literature has proven that teenage pregnancy among schoolgirls is a major distress in South Africa (Malahlela, 2012; Mashishi and Makoelle, 2014). In Namibia, high school learners are engaging in immature sexual relationships (Pazvakawambwa, Indongo and Kazembe, 2013, and Legal Assistance Centre [LAC]; 2012 and Nekongo-Nielsen \& Nchindo, 2013) which lead many girls to drop out of school due to unplanned pregnancy. In addition, Rima (2008) observed the majority of high school learners also engage in various misbehavior acts such drinking alcohol, stealing and abusing drugs bunking lessons to mention a few. Apart from poverty, peer pressure and environmental factors, problems are traced to have their foundations in the Admission Policy. United Nation Education Scientific and Cultural Organization [UNESCO] (2015) pointed out that some children clearly start school late and in some parts of the country some learners are admitted at the age of nine (9).

The age of the learners becomes a major cause of concern as children enter high school. By the time these learners reach high school, they are above the age of 16 which makes it difficult for the teachers to discipline them without brushing their shoulders with the arms of law - The Age of Consent. Johnson et al. (2011) are of the view that between the years of 15 and 18 children are undergoing a crisis stage where individuals are fighting for identity and recognition. The phase is defined as an interim stage from childhood to adulthood and is a stage of quick evolution in which physical, sexual and emotional modifications happen (Wolff, 2012). In concurrence, Reddy and Sinha (2010) states that most high school learners are engaging in alcohol abuse and unsafe sexual 
behaviors. Unprotected sexual relationship among high school learners has led to accidental pregnancies to girls between the ages of $10-19$ and this has become a grave health and social challenge (The Namibia Statistics Agency, 2012). This then becomes a challenge when a child is admitted to start school at the age of 7 because they become mini adults whilst in high school.

Late admission in primary school mostly causes learners to drop-out from school before the completion of the secondary phase. This paper has the opinion that The Namibian's School Admission Policy contributes in having adults in high schools instead of teenagers Ministry of Education, (Ministry of Education [MoE] Bill, 2018). According to Ministry of Education's Admission Policy in Namibia, a child must be turning 7 in Grade 1 and completes the 7-year primary course at 13. If it happens that the child repeats once in each primary school phase, he/she will be 15 by the time of completing Grade 7 (MoE, 2017). The high school has two phases and a learner is allowed to repeat once at each one. If this happens, the learner completes Grade 12 at the age of 22 or beyond. The implementation of the Pregnancy Policy has also added academic years of learners who fall victim of that. This has left the Education of the Namibian child under spotlight.

According to Tschombe et al, (2011) several studies have pointed out the serious problems of the Namibian educational system. They have substantiated that many of the problems are related to low performance when compared to other African countries. The high failure rate is a cause of concern as argued by UNESCO (2015). The Namibian government is on record for its unwavering support to the development of quality education. However, the outputs are not desirable if compared to the financial and human resource invested (MoE, 2008). The intention of the government to keep all children in the school and create a knowledge-based society is a noble idea. To achieve the national aim, the education system has several plans in place, such as the Pregnancy Policy. A decision was made by the MoE (2012) that if a girl child falls pregnant, she should continue with her studies until the time of giving birth. After that, she is allowed to re-join and continue with her studies. This has made it difficult for parents and school to control children that are above The Age of Consent (16).

In an endeavor to solve the existing problems, the government has revised the Promotion Policy to improve the number of learners proceeding to the next grade. However, those who fail to meet the expected competence levels are given the opportunity to repeat the level. In support of that, Sichombe et al, (2011) state that repetition comes from various dimensions which include voluntary caused by family, by language barrier or as a result of examination failure. While it can be argued to be a noble idea to repeat a grade, other researchers have a view that, repeating a grade has negative effects on learners' progress both academically and socially and also the learner becomes older for the grade (UNESCO, 2015). From a social perspective, leaners who are too old for their grades negatively influence others into deviant behavior such as substance abuse and sexual relations (Kapitako, 2017).

UNESCO (2006) recommended the government of Namibia for its commitment towards the wellbeing of children by signing The Convention on the rights of the child. The right to education is well enshrined in the Namibian constitution. A number of policies have been initiated and several programs are in place to address the developmental aspects of the learners. However, the most recent National Policy of MoE (2017) argues that educational stakeholders found it very necessary to develop a new curriculum and Promotion Policy to assist their learners sail through the high school phase. Nonetheless, this study examined the impacts of the Namibian School Admission Policy on high school leaners. Additionally, the study explored how the age of learners contradicts with the school rules and some country laws.

As of late, the concerned authorities in Namibian education have realized the problems and have been advocating for reforms. However, their efforts are being hampered by a number of limitations. Firstly, Namibia has a very small population of about 2.5 million people which is sparsely distributed. The situation makes it difficult for the government to build schools around the country to accommodate the scattered population. UNESCO (2015) indicated that population distribution in Namibia makes it impossible to build schools for all children. Children of farm workers, Khoisan and Ovahimba are mostly affected when it comes to enrolling late because they live in remote areas (UNESCO, 2015). Historically, they are semi-nomadic, meaning that the continuous movement is a challenge for children to successfully go through the learning phase without repeating. Even though the government has tried to establish mobile schools, the challenge of getting qualified teachers who 
can suit that lifestyle is another stumbling block. Moreover, the parent's value more of their culture and household chores such as herding cattle than schooling (UNESCO, 2015). Therefore, due to lack of parental support, learners repeat grades as they would have failed to meet the expected competence, and urban areas are affected by broken families (Parks, 2013).

\section{Method}

A quantitative research methodology together a cross-sectional research designs were used to contact this study (Creswell, 2008). Cross-sectional design gives the necessary base for further inquiry of the phenomenon under investigation. At the moment, no research was done in Windhoek concerning the impacts of the Namibian School Admission Policy on high school learners. The crosssectional design may suggest a base for further intervention studies.

In addition, a quantitative research method needs statistical analysis and inferences to refute or accept hypotheses for the investigated variables of the study (Bless, Higson-Smith and Kagee, 2006). Quantitative research was conducted using a diversity of methods which use quantities to record and investigate the authenticity of aspects being investigated (Kumar, 2005). The collected data was coded and recorded in statistical forms, to which analysis was done to explain the significance of the discoveries (Hirschstein et al., 2007). The yielded numerical data had a relative benefit and were able to be compute and calculate associations for large populations. Quantitative research takes an account of designs, techniques and measures that produce undistinguished statistical or numerical data (Kothari, 2006). This was to regulate the degree to which the Admission Policy impacts learners' behavior in high schools. For this reason, data collected was perceived with a higher degree of confidence. The assertion attained permits authorities and policy makers to discover contributory factors and make possible adjustments (Creswell, 2008). In this study a questionnaire with closed questions was used to collect data. The data was then statistical analyzed to see if there were any statistical correlations between the age of the participants and certain social trends displayed in schools.

Procedurally, permission was requested from the Regional Director of education to investigate whether the admission policy has an impact on high school learners in Namibia. Permission was then sought from school principals and parents to allow learners to participate in the study. Questionnaires were completed during normal Life Skills Lesson time ensuring minimum disturbances of the normal school timetable. The collected raw data was systematically and numerically coded, entered and cleaned in SPSS analysis (Bless, Higson-Smith and Kagee, 2010). The Statistical Package for the Social Science [SSPS] 24 was used to approve or reject the pre-defined hypothesis for ensuring relationships between variables under study (Babbie and Mouton, 2006). The cross-sectional design was used because it is the appropriate one to use when exploring relationships within a short period of time (Deslandes and Berthrand, 2005). The sample consisted of 200 participants who were randomly selected from five state secondary schools in Katutura, Windhoek. The probability sampling was used since it has a selection of a "random sample" from the list with names of high schools, grades and learners within the population of interest (Babbie and Mouton, 2006). The sample had hundred and eleven (111) girls and eighty-nine (89) boys' learners from different ethnic groups from grades 8 to 12. The Section A of the questionnaire needed demographic information from participants such as gender, age and grade. Section B contained closed questions which required participants to indicate how they had behaved or interacted with others at school within the previous year. The questionnaire was in English and those participants who could not read were helped to understand the questions while confidentiality of answers was being observed.

\section{Results}

The obtained results of the conducted statistical enquiry that was done for the study are displayed in this section. The results are presented as (1) descriptive on how the Namibian School Admission Policy has permitted learners to become adults while they are still in schools and (2) the interactive characteristics between age and behavioral traits. The SPSS 24 using Pearson Chi- squares and Spearman Correlations and standard deviations were used for all the statistical calculations. 
DOI: 10.21522/TIJAR.2014.SE.19.01.Art002

ISSN: $2520-3088$

\section{Presentation and analysis of respondents' bio -data}

\section{An overview of the analyses}

The hypothesis below for this study was framed as follows:

Alternative Hypothesis: The Namibian School Admission Policy has an impact on high school learners in Namibia. This hypothesis was tested by independent $t$ tested by a Pearson Product-Moment correlation.

Null Hypothesis: The Namibian School Admission Policy has no impact on high school learners. This hypothesis was tested by a Standard Deviation (SD).

\section{Internal consistencies of measures}

The instrument used in this study was the Youth Self -Report [YSR], Achenbach and Edelbrock, 1987) questionnaire. It measured the behavioral traits of the high school learners. A test reliability test technique was used applying the Cronbach alpha that needed only a single test administration to provide a unique estimate of the administered test (Gliem, et al, 2003). Table 1 shows the Cronbach alpha coefficients for behavioral traits of the high school learners.

Table 1. Internal consistencies of misbehavior among high school learners

\begin{tabular}{|l|}
\hline Instrument $\mathrm{n}$ (items) Alpha \\
\hline YSR 15 .85 \\
\hline
\end{tabular}

The Cronbach Alpha coefficient for the YRS was. 85. The obtained Cronbach Alpha coefficient is within the usual parameters according to Mckillup (2006) because they it is above .75 . Hence, the instrument was considered dependable.

\section{A description of the adolescents' demographic set up}

\section{Gender}

Demographics were measured using a Questionnaire Demographic Survey which asked participants to indicate their gender, age and Grade. There were more girls who participated in this study. Figure 1 indicates the total number of high school learners who participated in the study according to gender.

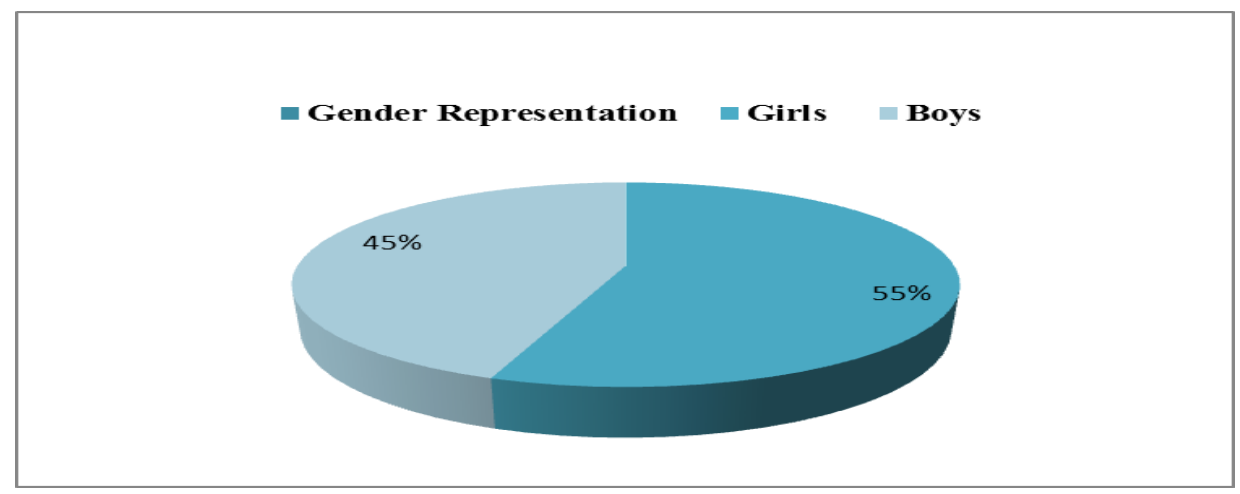

Figure 1. The distribution of participants according to gender

The sample had hundred and eleven (111) girls (55\%) and eighty-nine (89) boys (45\%) from five state schools ranging from grades 8 to 12 . The data was collected during examination time. This may be was the cause the imbalance of numbers as per gender and grade because only those who had examination the day of collecting data were present and a few from other grades who came to study. 


\section{Grade}

\section{Grade representation}

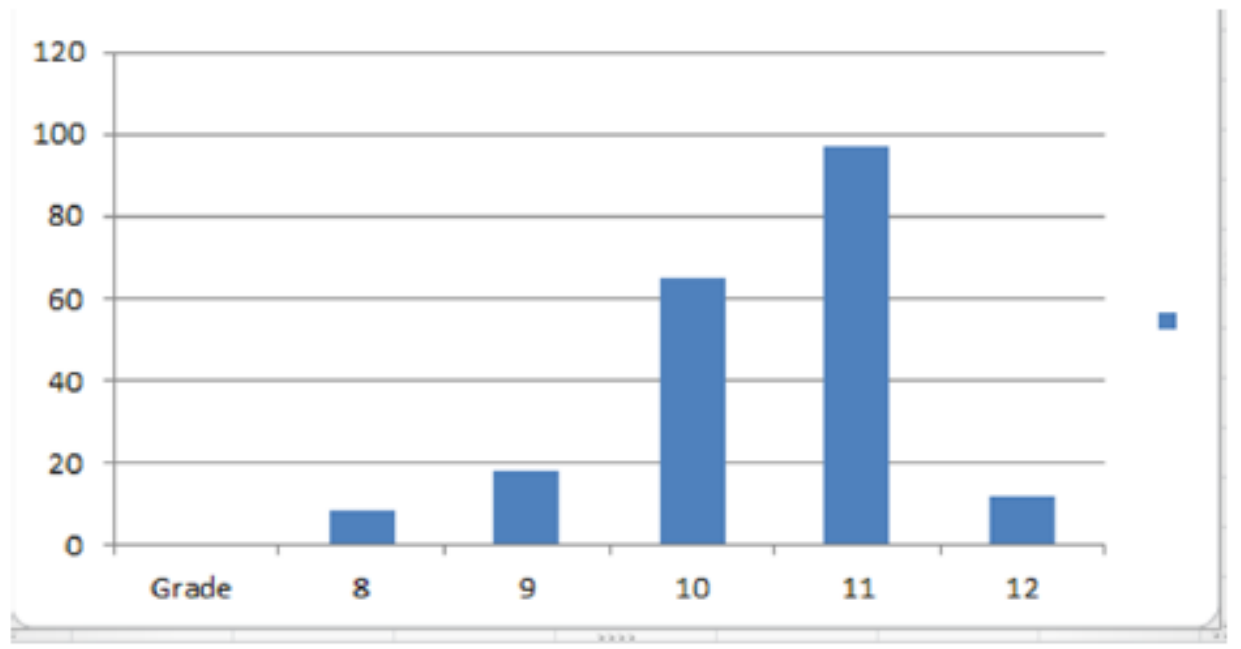

Figure 2. Shows the number of participants according to grade.

Most of the participants were Grade 11 learners (97: 48.5\%) because it was their examination day. Grade 10 learners had a revision session in one of the visited schools that's why they were a bit more than other grades too. However, it must be also mentioned that the results obtained do not point to an explicit grade. The results in Table 2 show the age of participants as per Grade. The youngest was 15 years old and the oldest was aged 34 .

Table 2. The age of participants as per Grade

\begin{tabular}{|l|r|r|r|r|r|r|r|r|r|r|} 
Age & $\mathbf{1 5}$ & $\mathbf{1 6}$ & $\mathbf{1 7}$ & $\mathbf{1 8}$ & $\mathbf{1 9}$ & $\mathbf{2 0}$ & $\mathbf{2 1}$ & $\mathbf{2 2}$ & $\mathbf{2 3 +}$ & Total \\
\hline $\begin{array}{l}\text { Grade } \\
8\end{array}$ & 1 & 2 & 2 & 1 & 0 & 1 & 1 & 0 & 0 & 8 \\
\hline $\mathbf{9}$ & 2 & 6 & 8 & 1 & 1 & 0 & 0 & 0 & 0 & 18 \\
\hline $\mathbf{1 0}$ & 1 & 37 & 21 & 1 & 3 & 2 & 0 & 0 & 0 & 65 \\
\hline 11 & 0 & 0 & 8 & 18 & 18 & 18 & 10 & 6 & 4 & 97 \\
\hline 12 & 0 & 0 & 2 & 3 & 3 & 4 & 0 & 0 & 0 & 12 \\
\hline Totals & $\mathbf{4}$ & $\mathbf{4 5}$ & $\mathbf{4 1}$ & $\mathbf{2 4}$ & $\mathbf{2 5}$ & $\mathbf{2 5}$ & $\mathbf{1 1}$ & $\mathbf{6}$ & $\mathbf{4}$ & $\mathbf{2 0 0}$ \\
\hline
\end{tabular}

Table 2 shows that 76 (38\%) of the participants have reached The Age of Consent and 95 (47.5\%) of them were 18 years old and above and are allowed by law to drink alcohol and to smoke. Meaning $181(90.5 \%)$ of the participants are somehow protected by country laws that contradict with the school rules (MoE, Bill 2018).

Table 3 represents the mean and standard deviation totals for each of the 15 variables of the YSR (ASB) for all the participants according to age. 
DOI: 10.21522/TIJAR.2014.SE.19.01.Art002

ISSN: $2520-3088$

Table 3. Means and SD for items of participants' behavioral traits

\begin{tabular}{|l|r|r|}
\hline Behavioral Traits of high school learners during the past year & \multicolumn{2}{|c|}{ N $=\mathbf{2 0 0}$} \\
\cline { 2 - 3 } Have you done any of the following at or around school with friends or alone? & Mean & \multicolumn{1}{|c|}{ SD } \\
\hline 1. Bullied (threatened, harassed, fought or beat another learner & 1.34 & 0.56 \\
\hline 2. Pretended to be sick in order to stay away from school. & 1.24 & 0.51 \\
\hline 3. Brought home clothes to school without permission & 1.45 & 0.59 \\
\hline 4. Not done school work or homework & 1.09 & 0.31 \\
\hline 5. Missed out lessons/ school & 1.15 & 0.22 \\
\hline 6. Lied to a teacher(s) & 1.27 & 0.57 \\
\hline 7. Be on facebook/WhatApp/ twitter during lessons(use a cellphone) & 1.56 & 0.73 \\
\hline 8. Cheated during tests/exams or another learner & 1.73 & 0.67 \\
\hline 9. Fallen in love with a boy/girl & 1.42 & 0.65 \\
\hline 10. Disrespected teachers & 1.16 & 0.22 \\
\hline 11. Had sexual relationships & 1.92 & 0.75 \\
\hline 12. Drank alcohol & 1.48 & 0.66 \\
\hline 13. Smoked cigarettes/ hubbly bubbly & 1.75 & 0.68 \\
\hline 14. Used drugs for non medicinal purposes & 1.37 & 0.46 \\
\hline 15. Brought dangerous object toschool (a knife/ screwdriver) etc. & 1.28 & 0.58 \\
\hline Totals & 1.08 & 0.28 \\
\hline Percentages & 1.44 & 0.59 \\
\hline Final Percentages & 1.32 & 0.54 \\
\hline
\end{tabular}

The highest mean scores are found for the item "Had sexual relationship $(s)(M=1.92, S D=.75)$. The second highest mean scores are found for the items "Failed to do your school work/ homework" $(\mathrm{M}=1.85, \mathrm{SD}=.35)$ and "Had cheated during tests/exams or another learner" $(\mathrm{M}=1.75, \mathrm{SD}=.67)$. The lowest mean score is found for the item "had brought dangerous object(s) to school -e.g knife/school driver" $(\mathrm{M}=1.08,=\mathrm{SD}=.28)$.

Table 4. Frequencies of items on behavioral traits of participants during the past year

\begin{tabular}{|c|c|c|c|c|c|c|c|c|c|c|c|c|c|c|c|c|c|c|}
\hline \multirow{2}{*}{$\begin{array}{l}\text { Indiridual Beharior Checklist Questions } \\
\text { Have you ever done any of the following at or }\end{array}$} & & & & \multicolumn{15}{|c|}{ Frequencies on behavior as per age } \\
\hline & & 15 & & 16 & & 17 & & 18 & & 19 & & 20 & & 21 & & 22 & & $23+$ \\
\hline around school with friends or alone? & Yes & $\mathrm{N}_{0}$ & Yes & $\mathrm{N}_{0}$ & Yes & $\mathrm{N}_{0}$ & Yes & & Yes & $\mathrm{N}_{0}$ & Yes & $\mathrm{N}_{0}$ & Yes & $\mathrm{N}_{0}$ & Yes & No & Yes 1 & No \\
\hline 1. Bullied (threatened, harassed, fought or beat another learner & 2 & 2 & 26 & 19 & 15 & 26 & 18 & 6 & 14 & 11 & 12 & 8 & 6 & 5 & 3 & 3 & 9 & 10 \\
\hline 2. Pretended to be sick in order to stay away from school. & 3 & 1 & 32 & 13 & 24 & 17 & 16 & 8 & 20 & 5 & 16 & 4 & 7 & 4 & 3 & 3 & 1 & 18 \\
\hline 3. Brought home clothes to school without permission & 1 & 3 & 28 & 17 & 36 & 5 & 12 & 12 & 16 & 9 & 13 & 7 & 8 & 3 & 2 & 4 & 14 & 5 \\
\hline 4. Not done school work or hometwork & 2 & 2 & 36 & 9 & 32 & 9 & 18 & 6 & 18 & 7 & 14 & 6 & 10 & 1 & 4 & 2 & 10 & 9 \\
\hline 5. Missed out lessons/school & 0 & 4 & 30 & 15 & 29 & 12 & 13 & 11 & 17 & 8 & 9 & 11 & 4 & 7 & 2 & 4 & 5 & 14 \\
\hline 6. Lied to a teacher(s) & 4 & 0 & 39 & 6 & 21 & 20 & 15 & 9 & 12 & 13 & 17 & 3 & 5 & 6 & 4 & 2 & 5 & 14 \\
\hline 7. Be on facebook/WhatApp/twitter during lessons(use a cellphone) & 0 & 4 & 21 & 24 & 32 & 9 & 10 & 14 & 15 & 10 & 6 & 14 & 4 & 7 & 3 & 3 & 7 & 12 \\
\hline 8. Cheated during tests exams or another learner & 3 & 1 & 42 & 3 & 25 & 16 & 8 & 16 & 19 & 6 & 18 & 2 & 9 & 2 & 4 & 2 & 13 & 6 \\
\hline 9. Fallen in love with a boy girl & 3 & 1 & 40 & 5 & 39 & 2 & 22 & 2 & 24 & 1 & 17 & 3 & 8 & 3 & 6 & 0 & 17 & 2 \\
\hline 10. Distespected teachers & 0 & 4 & 22 & 23 & 25 & 16 & 11 & 13 & 10 & 15 & 2 & 18 & 3 & 8 & 0 & 6 & 2 & 17 \\
\hline 11. Had sexual relationships & 2 & 2 & 27 & 18 & 23 & 18 & 19 & 5 & 20 & 5 & 16 & 4 & 10 & 1 & 4 & 2 & 15 & 4 \\
\hline 12. Drank alcohol & 2 & 2 & 37 & 8 & 38 & 3 & 19 & 5 & 20 & 5 & 15 & 5 & 8 & 3 & 3 & 3 & 13 & 6 \\
\hline 13. Smoked cigarettes/ hubbly bubbly & 2 & 2 & 25 & 20 & 31 & 10 & 15 & 9 & 17 & 8 & 7 & 13 & 4 & 7 & 3 & 3 & 12 & 7 \\
\hline 14. Used drugs for non medicinal purposes & 2 & 2 & 21 & 24 & 25 & 16 & 13 & 11 & 7 & 18 & 11 & 9 & 6 & 5 & 2 & 4 & 10 & 9 \\
\hline 15. Brought dangerous object toschool (a knife/ screwdriver) etc. & 0 & 4 & 2 & 43 & 4 & 37 & 4 & 20 & 4 & 21 & 3 & 17 & 4 & 7 & 1 & 5 & 4 & 15 \\
\hline Totals & 26 & & 428 & & 399 & & 213 & & 233 & & 176 & & 96 & & 44 & & & 148 \\
\hline
\end{tabular}

Results shown in Table 4 indicates that most learners between the ages of 16 and 19 had behavior problems. Most participants indicated that they had fallen in love (87\%), 78\% had drank alcohol and $72 \%$ had not done their homework or school work. Some variables were less violated. For example, only $13 \%$ of the participants had brought dangerous objects to school and $38 \%$ of them had disrespected the teachers. 


\section{Discussions}

\section{Introduction}

This section integrates the results in Chapter 3 in order to discuss the posed hypothesis of the study. Also, the limitations of the study will then be pronounced, the conclusion will be clearly defined and recommendations for future researchers will be stated.

\section{Gender}

The results displayed that most of the participants were girls (55\%) and boys were $45 \%$. Nonetheless, issues such as parental involvement, poor performance, substance abuse and more importantly, parental care and support have added in taking the boy child away from school (Cooper, 2012 and Kapitako, 2017). If this happens, they then drop out of school. Apart from this, the involvement in delinquent behavior such as hooliganism, robbery and violent behavior had driven most of them to be expelled from school. For girls, the Pregnancy Policy has protected them since they are allowed to rejoin the education system after giving birth (The Namibia Statistics Agency, 2014).

\section{Age and grades}

The age of participants ranged from 15 to 34 . The majority of the participants' age ranged from 1620 years old of which is the most critical stage of life since individuals fight for identity and gratitude (Johnston et al., 2011). It is also puzzling to understand why 21-year-olds and up are still in high school? This is promoted by the Education Policies that are in place, like the School Admission Policy, where children turn 7 years in their first grade. On top of that, the Repeating, Promotional and Transfer Policies encourage learners to age whilst they are still labeled as school children whereas in reality they are already adults (Ministry of Education Admission Policy, 2018; Ministry of Education Promotional; Pregnancy Policy, 2016 and Transfer Acts, 2018 \& the Revised Education Bill, 2018). These circumstances confuse the children as they reach the age of 16, because of The Age of Consent Act allows them to engage in sexual activities. The Age of Consent Act stipulates the minimum age at which an individual is considered legally old enough to consent participation in sexual activity. Alcohol intake and smoking bring the same confusion to the situation. These commodities are sold to persons over 18 years of age and it is legal. The School Rules then contradict with the country law. If these children are allowed by the country regulations to indulge into drinking and smoking because they are adults, will there be a balance on academics and their social behaviors? Hence, the origination of misbehavior in schools which leads to school drop-outs, teenage pregnancies and substance abuse. As shown in Table 2, 47.5\% of the participants were 18 year old and above, how can teachers then discipline these adults in the classroom?

The age of learners has opened doors for substance use among them. As shown on Table 3 and 4, $61 \%$ of the learners indicated that they had used drugs such as alcohol, hubbly bubbly and cigarettes. $77 \%$ of the respondents had fallen in love and indulged in sexual activities. The root cause of such behaviors is the above mentioned policies in place. Evidence that most high school learners are sexually active corresponds well with Malahlela, (2012); and Mashishi and Makoelle, (2014)'s findings on high rates of unplanned pregnancies among leaners. These policies accommodate a 23 year old and above person to be still in school. Above all, the Age of Majority Act starts at 21 year, but at 18 years one is legally allowed to smoke and drink alcohol.

\section{Behavior traits of high school learners}

According to Table 4, the frequencies of items on behavioral traits of participants during the past year show that most of the participants had drifted away from the school rules in one way or another. Responses in Table 4, displayed that these school going age people are already sexually active and are smoking and using drugs for non-medicinal purposes. This is maybe the major cause of high rates of pregnancies in schools, dropping out and poor academic performance in Windhoek. Learners are engaging in activities that destroy them instead of studying. Literature has confirmed that high school learners (Rima, 2008; LAC; 2012, and Nekongo-Nielsen and Nchindo, 2013) engage in the mentioned risky acts. On the other hand, the law declares that it is their right because of their age. The behavior 
problems from the learners were an indication that age was playing a major role. The findings are supported by UNESCO (2015) by pointing out that despite the policy; learner pregnancy continues to contribute to young girls dropping out of school. T

It was also observed that bullying was evident in schools. 53\% of the respondents indicated that they had bullied others during the past year. It is not surprising that this offence is common in schools and as it is associated with learners who are well versed with the school system. In high school, the grade 8 learners are the main victims since they will be still new and younger from primary school. Responses show that learners in the 16 to 17 age group are major offenders of this transgression. These learners agreed to have beaten, harassed or threatened other learners. This concurs with UNESCO (2015) who states that learners that repeat grades become older than their classmates, hence bullying takes place.

The results in Table 3 and 4 indicated that social media has become the problem of young generations. The responses (49\%) showed that learners do visit social media websites during learning times. Most learners between the age of 17 and 19 have agreed that they had used various social media platforms during learning time. This explains why 55\% of the respondents had missed out on school lessons.

\section{Conclusion}

It has been discovered that the majority of learners in high schools fall under certain laws that allow them to act as adults whilst they are still teenagers. For example, The Age Consent Act allows a 16-year-old to make decisions on sexual matters while they are still staying with parents. This has opened doors for teenage pregnancies, sexually transmitted diseases, abortions and baby dumping cases that Windhoek is facing. The policies have left learners very vulnerable since they start school late and as they reach high school, most of them are already adults. This study has also discovered that people over the age of 18 are still in high school and are permitted by law to smoke if they wish. When they mingle or socialize with the underage learner's peer influence takes over and the innocent ones if not careful, they are trapped in. The hidden curriculum then takes over and those who are under 16 or 18 are left exposed. So, what educational stakeholders see as mischief in some learners is not, because they are behaving according to their age and no one can fight against nature. It is really hard to imagine a discussion that goes on between a 23 plus year old learner and a 13 -year-old learner during school break time at school. It can then be concluded that schools are challenged by behavioral problems as a result of the age of the learners. However, as worrying and multifaceted the situation may appear, there are methods that can be implemented to rescue those who start school earlier than 7 years to minimize their conversion to ill behavior traits for the better.

\section{Recommendations}

The emphasis of this open-minded research has often focused on the impacts of the Namibia School Admission Policy on High School Learners. Dynamic perceptions were provided in this study to broaden our understanding why some high school learners behave the way they do. The following recommendations are grounded on the results of this study;

- The Government of Namibia should revise the Sexual Consent age and must be from the age of 21 not 16.

- The Ministry of Education should revise the Education Bill, the regulations and Acts concerning the School Admission Age, Promotion-transfer of learners and the Pregnancy Policy.

- There must be specific schools for learners who are over 18 years of age. They must not be allowed to mix or interact with learners who are still under National Laws.

\section{References}

[1]. Babbie, E. and Mouton, J., 2006, The practice of social scienceS research. South Africa: Oxford University Press.

[2]. Bless C., Higson-Smith C., and Kagee A., 2006, Fundamentals of social research methods. An African perspective, (4th Ed) Cape Town: Juta and Co.

[3]. Cresswell, J. W., 2008, Educational research: Planning conducting, and evaluating quantitative and qualitative research. ( $3^{\text {rd }}$ Ed). New Jersey: Pearson Prentice Hall. 
[4]. Deslandes, R., and Berthrand, R., 2005, Motivation of parent involvement in secondary-level schooling. The journal of Educational Research, 98(33): 164-175.

[5]. Edelman, A. (1995). "Effects of Social Reinforcement on Isolate Behavior of a Nursery School Child", Child Development 35 (2): 511-518.

[6]. Gliem, F., and Glem, R., 2003, Calculating, Interpreting and Reporting Cronbach's Alpha Reliability Coefficient of Likert Type Scales. Conference in Adult, Continuing and Community Education.

[7]. Hirschstein, M. K., Edstrom, L V. S., Frey, K. S., Snell, J. L. and MacKenzie P. E., 2007, Walking the Talk in Bullying Prevention: Teacher Implementation Variables Related to Initial Impact of the Steps to Respect Program.

[8]. Hirschstein, M. K., Leihua Van Schoiack, E., Frey, K. S., Snell, J. L., and MacKenzie, E. P., Committee for Children, Seattle, , Vol. 36, Washington School Psychology Review, pp. 3-21

[9]. Johnston, L. D., O’Malley, P. M., Bachman, J. G., and Schulenberg, J. E., 2011, Monitoring the future national survey results on drug use, 1975-2010: Volume II, College students and adults ages 19-50. Ann Arbor, MI: Institute for Social Research.

[10]. Kapitako. A., 2017, Hubbly- bubbly; a threat to public health. New Era March 3https://www.newera.com.na/2017/03/03/hubbly-bubbly-a-threat-to-public-health/

[11]. Kothari, C. R., 2008, Research Methodology: Methods and Techniques, (2nd Ed). New Delhi: New Age International (P) Publishers.

[12]. Legal Assistance Centre. (2008). School Policy on Learner Pregnancy in Namibia: Background to Reform. Windhoek. Legal Assistance Centre. John Meinert Printing (Pty) Ltd.

[13]. Lloyd, C. B. and Hewett, P. C., 2009, Poverty, gender and youth: Educational inequalities in the midst of persistent poverty: Diversity across Africa in Educational outcomes. New York: Population Council, Working paper No. 14. Date of access: 2/11/2018. www.popcouncil.org/publications/wp.asp.

[14]. Malahlela, M. K., 2012, The effect of teenage pregnancy on the behaviour of learners at secondary schools in the Mankweng area, Limpopo. M Ed dissertation. Pretoria: UNISA

[15]. Mashishi N., and Makoelle T., 2014, Inclusion or Exclusion Ramifications of Teenage Pregnancy: A Comparative Analysis of Namibia and South African Schools Pregnancy Policies. Mediterranean Journal of Social Sciences Vol 5(14), MCSER Publishing, Rome-Italy

[16]. Mckillup, S., 2006, Statistics Explained: An Introductory Guide for Life Scientists. Cambridge: University Press.

[17]. Ministry of Education, 2011, Free primary education in Namibia. Current context, John Menert Printing, Windhoek.

[18]. Ministry of Education, 2017, National Promotion Policy guide for junior and senior secondary schools phases. NIED, Okahanja.

[19]. Ministry of Education Arts and Culture, 2016, Survey Report: Towards a new education act for Namibia. Government Press, Windhoek.

[20]. Mouton, J., and Marais, H. C., 1996, Basic concepts in the methodology of the social sciences. Pretoria, HSRS Publishers.

[21]. Namibia Statistics Agency (2012). Namibia Household Income \& Expenditure Survey (NHIES) 2009/2010. Windhoek: Namibia Statistics Agency.

[22]. Nekongo-Nielsen, H. \& Mbukusa, N. R., 2013, The educational consequences of teenage pregnance in the Kavango Region. Journal for Studies in Humanities and Social

[23]. Parks, A. B., 2013, The effects of family Structure on juvenile delinquency. Electronic Theses and Dissertations. Paper 2279. http://dc.etsu.edu/etd/2279

[24]. Pazvakavambwa, L., Indongo, N., and Kazembe, L. N., 2013, Explaining marital patterns and trends in Namibia: A regression analysis of 1992, 2000 and 2006 Demographic and Survey DataPLoS One. 8(8): e70394. DOI: 10.1371/journal.pone.0070394 PMCID: PMC3744526 PMID: 23967073 pregnancy in the Kavango Region, University of Namibia.

[25]. Reddy, A. N., and Sinha, S., 2010, School dropouts or pushouts? Overcoming barriers for the right to education. CREATE Research Monograph No. 40, July 2010. National University of Educational Planning and Administration (NUEPA).

[26]. Rima, B. M. D., 2008, Causes of peer pressure. ww.well.sphere.co/wellpage/causes of peer pressure. 
DOI: 10.21522/TIJAR.2014.SE.19.01.Art002

ISSN: $2520-3088$

[27]. Sichombe, B., Nambira,G., Tjipueja, G and Kapenda, L., 2011, Evaluation of promotion policy requirements in Namibian schools. NIED, Okahanja.

[28]. UNESCO, 2015, School drop-out and out of school children in Namibia: A national review 2015. (Abriged version). UNICEF, Windhoek.

[29]. UNESCO, 2015, School drop-out and out of schoolchildren in Namibia. A national review. UNICEF: Windhoek.

[30]. Wolff, J. M., 2012, Adolescent decision making and risk behavior: A neurobiological approach. Theses, Dissertations, and Student Research, Department of Psychology (41). http://digitalcommons.unl.edu/psychdiss/ 